\title{
Predictors of long-term survival prior to permanent pacemaker implantation in octogenarians or older
}

\author{
Chi-Wen Cheng ${ }^{1,2}{ }^{\oplus} \cdot$ Chao-Hung Wang ${ }^{1,2} \cdot$ Wei-Siang Chen ${ }^{1} \cdot$ Chun-Chieh Wang ${ }^{2,3} \cdot$ Wen-Jin Cherng ${ }^{2,3}$
}

Received: 18 March 2018 / Accepted: 21 September 2018 / Published online: 27 September 2018

(c) The Author(s) 2018

\begin{abstract}
Background There is an increased need for permanent pacemaker (PPM) implantation for older patients with multiple comorbidities. The current guidelines recommend that, before implanting PPM, clinicians should discuss life expectancy with patients and their families as part of the decision-making process. However, estimating individual life expectancy is always a challenge.

Aims We investigated predictors of long-term survival prior to PPM implantation in patients aged 80 or older.

Methods and results From September 2004 to September 2015, 100 patients aged $\geq 80$ years who received PPM implantation were included for retrospective survival analysis. The end point was all-cause mortality. Follow-up duration was $4.0 \pm 2.7$ years. By the end of the study, 54 patients $(54 \%)$ had died. Of the 54 who died, 40 patients $(74.1 \%)$ died of noncardiac causes. Their survival rates at $1,2,3,5$, and 7 years were $90 \%, 76 \%, 54 \%, 32 \%$, and $16 \%$, respectively. Patients with a longer length of hospital stay before PPM implantation (LOS-B) [hazard ratio (HR) $1.03,95 \%$ confidence interval (CI) 1.02-1.05, $p<0.001$ ], estimated glomerular filtration rate (eGFR) $<30 \mathrm{ml} / \mathrm{min} / 1.73 \mathrm{~m}^{2}$ (HR 4.07, 95\% CI 1.95-8.52, $p<0.001$ ), body mass index (BMI) $<21 \mathrm{~kg} / \mathrm{m}^{2}$ (HR 2.50, 95\% CI 1.16-5.39, $p=0.02$ ), and dyspnea as the major presenting symptom (HR 2.88, 95\% CI 1.27-6.55, $p=0.01$ ) were associated with lower cumulative survival.

Conclusions Longer LOS-B, lower eGFR and BMI, and dyspnea as the major presenting symptom are pre-PPM implantation predictors of long-term survival in patients aged 80 or older.
\end{abstract}

Keywords Pacemaker $\cdot$ Octogenarian $\cdot$ Geriatrics $\cdot$ Survival $\cdot$ Frailty

\section{Introduction}

The world population is aging. According to the World Population Prospects reported by the United Nations, the number of people aged 80 or above is projected to triple from 137 million in 2017 to 425 million in 2050 [1]. The aging population results in progressively increasing need for permanent pacemaker (PPM) implantation for older patients with multiple comorbidities [2]. The current guidelines

Chi-Wen Cheng

aneasyway@gmail.com

1 Heart Failure Research Center, Division of Cardiology, Department of Internal Medicine, Chang Gung Memorial Hospital, 222 Mai Chin Road, Keelung, Taiwan, ROC

2 Chang Gung University College of Medicine, Taoyuan, Taiwan, ROC

3 Division of Cardiology, Chang Gung Memorial Hospital, Linkou, Taiwan, ROC recommend that clinicians discuss the probability of living more than 1 year with patients and their families during decision-making about PPM implantation [3]. However, estimating individual life expectancy before the procedure is always a challenge. Data on pre-PPM implantation predictors of long-term survival in patients aged 80 or older have been limited. Most previous studies on this topic were carried out at least 10 years ago and do not reflect the current situation [4-6]. A landmark study by Udo et al. in 2012 included many important baseline characteristics as possible predictors [7] but lacked clinical data such as symptoms, left-ventricle ejection fraction (LVEF), estimated glomerular filtration rate (eGFR), and length of hospital stay. Recent studies have begun to pay more attention to the relation between survival and these variables in geriatric patients [8-11]. For this study, we hypothesized that these clinical variables prior to PPM implantation predict long-term survival in patients aged 80 or older. A better understanding of 
their prognosis before PPM implantation is informative for decision-making in the clinical setting.

\section{Methods}

\section{Patients}

This study included patients age $\geq 80$ years who met the indications for chronic cardiac pacing [3] and received PPM implantation in Keelung Chang Gung Memorial Hospital from September 2004 to September 2015 for retrospective analysis. The Keelung Chang Gung Memorial Hospital is a 1098-bed, non-profit proprietary, metropolitan hospital. Patients who received cardiac resynchronization therapy, implantable cardioverter defibrillator, or pacemaker generator replacement were excluded. We collected the patients' clinical characteristics by chart review. These included age, gender, body weight, body height, serum creatinine level, initial major symptoms, indications for PPM implantation, admission to hospital via emergency department (ED) or out-patient department (OPD), length of stay before PPM implantation (LOS-B), and comorbidities, including hypertension, diabetes mellitus, coronary artery disease (CAD), atrial arrhythmia, old cerebral vascular accident, chronic obstructive pulmonary disease, and echocardiography results.

\section{Follow-up after discharge and major end point}

The patients returned to pacemaker OPD 1-2 weeks after discharge. After the first visit, the follow-up intervals were extended from 1-3 months, then to 6 months, depending on the patient's condition and physician's decision. On each follow-up visit, physicians assessed wounds, PPM function, the patient's general health, and adjusted the PPM settings as needed. Survival status and causes of death were obtained from chart review. When patients were lost to follow-up for more than 3 months, we used telephone contact to obtain the reasons for their absence and their vital status. Follow-up was completed on December 15, 2017. The end point was all-cause mortality.

\section{Definitions}

\section{CAD}

Patients who met any one of the following criteria were defined as having CAD: (1) history of acute myocardial infarction (AMI); prior percutaneous coronary intervention or coronary artery bypass surgery, (2) $\geq 50 \%$ coronary artery stenosis documented by invasive coronary angiograms or multislice computed tomography angiography, (3) positive results on noninvasive stress tests, for example, treadmill exercise electrocardiogram or thallium-201 single-photon emission tomography.

\section{Atrial arrhythmias}

History of atrial fibrillation, atrial flutter, or sustained atrial tachycardia documented on electrocardiography.

\section{Echocardiography}

All patients received echocardiography examinations during the month preceding PPM implantation. We reviewed the echocardiography results as follows: LVEF was calculated based on Simpson's method or the M-mode method according to the patient's clinical condition. Valvular heart disease was defined as a history of valve surgery or at least moderate severity valve dysfunction assessed in accordance with the practice guidelines [12].

\section{Estimated glomerular filtration rate (eGFR)}

eGFR was calculated using the Modification of Diet in Renal Disease formula: eGFR $\left(\mathrm{ml} / \mathrm{min} / 1.73 \mathrm{~m}^{2}\right)=186.3 \times($ serum creatinine $\mathrm{mg} / \mathrm{dl})^{-1.154} \times(\text { age })^{-0.203} \times 0.742$ (if female). We categorized the eGFR values as $>60,30-60$, and $<30 \mathrm{ml} /$ $\min / 1.73 \mathrm{~m}^{2}$, with the upper range based on the definition of chronic kidney disease (CKD) [13]. The lower range was based on the definition of CKD stage IV [13], and the findings of eGFR $<30$ were associated with increased risk for all-cause mortality in older patients [14].

\section{Body mass index (BMI)}

BMI was calculated by dividing body weight in kilograms by the square of body height in meters. BMI values were categorized as $>27,21-27$, and $<21 \mathrm{~kg} / \mathrm{m}^{2}$. The upper range was based on the Taiwanese definition of obesity [15]. The lower range was based on the population-specific cut-off point for low BMI on the Mini-Nutritional Assessment for older Taiwanese [16].

\section{Causes of death}

Death due to cardiac causes was defined as death resulting from AMI, congestive heart failure (CHF), ventricular tachycardia, ventricular fibrillation, or death without clear non-cardiac causes. PPM-related death was defined as death related to lead or generator dysfunction, and/or any procedure complications like infection, pneumothorax, or cardiac tamponade. 


\section{Statistical analysis}

The data are expressed as the mean \pm the standard deviation for normally distributed continuous variables, medians (lower quartile; upper quartile) for skewed variables, and number (percentage) for categorical variables. We used the Cox regression analysis to assess the effects of different variables on survival. The variables with a $p$ value of $<0.2$ in univariate analysis were included in the multivariate analysis. Hazard ratios (HRs) and $95 \%$ confidence intervals (CIs) were also calculated. We assessed the differences in LOS-B between groups using the Mann-Whitney $U$ test. The survival curve after PPM implantation was plotted using the Kaplan-Meier method and statistical significance was determined by the log-rank test. A $p$ value of $<0.05$ was considered statistically significant. Statistical analyses were performed using SPSS Statistics 17.0.

\section{Results}

\section{Patient characteristics}

Of the 230 patients receiving PPM implantation from September 2004 to September 2015, 106 patients (46.1\%) were aged 80 and above. Follow-up was completed for 100 (94.3\%) of these patients (52 men and 48 women). During follow-up, six patients were lost to contact with vital status unknown and were thus excluded from the following analysis. The age at implantation was $84.5(81.3 ; 88.0)$ years. Most patients were admitted from the ED. The majority of patients presented with dyspnea, followed by dizziness, syncope, or near syncope (Table 1). Low eGFR $(<30 \mathrm{ml} /$ $\left.\mathrm{min} / 1.73 \mathrm{~m}^{2}\right)$ and low BMI $\left(<21 \mathrm{~kg} / \mathrm{m}^{2}\right)$ were noted in 39 patients (39\%) and 17 patients (17\%), respectively.

The patients' LVEFs were normal. Atrioventricular conduction dysfunction (AVCD) was the most common indication for PPM implantation, followed by sick sinus syndrome (SSS) and atrial fibrillation with slow ventricular response (AFSVR). Atrial arrhythmias were noted in 39 patients (39\%). The median of LOS-B was 6 days. Eighty patients $(80 \%)$ received dual-chamber (DDD or DDDR mode) PPM implantation and the others (20\%) received single-chamber (VVI or VVIR mode) PPM implantation. Baseline characteristics are shown in Table 1.

\section{PPM implantation-related complications and causes of death}

PPM implantation-related complications occurred in five patients (5\%). No procedure-related mortality occurred. Of the five patients with complications, three developed pocket hematoma, one developed pneumothorax, and one developed
Table 1 Baseline characteristics of patients receiving permanent pacemaker implantation aged 80 or over $(n=100)$

\begin{tabular}{ll}
\hline Characteristics & \\
\hline Follow-up duration (years) & $4.0 \pm 2.7^{\mathrm{a}}$ \\
Age at implantation (years) & $84.5(81.3 ; 88.0)^{\mathrm{b}}$ \\
Male gender, $n(\%)$ & $52(52.0)$ \\
Admitted from emergency department, $n(\%)$ & $72(72.0)$ \\
Left-ventricle ejection fraction $(\%)$ & $68(62 ; 73)^{\mathrm{b}}$ \\
Major presenting symptom & \\
Syncope, near syncope, $n(\%)$ & $24(24)$ \\
Dizziness, $n(\%)$ & $26(26)$ \\
Dyspnea, $n(\%)$ & $50(50)$ \\
Comorbidities & \\
Hypertension, $n(\%)$ & $88(88.0)$ \\
Diabetes mellitus, $n(\%)$ & $33(33.0)$ \\
Coronary artery disease, $n(\%)$ & $25(25.0)$ \\
Valvular heart disease, $n(\%)$ & $24(24.0)$ \\
Cerebral vascular accident, $n(\%)$ & $23(23.0)$ \\
Chronic obstructive pulmonary disease, $n(\%)$ & $19(19.0)$ \\
Atrial arrhythmia, $n(\%)$ & $39(39.0)$ \\
eGFR (ml/min/1.73 m $\left.{ }^{2}\right)$ & $50.2(26.2 ; 66.8)^{\mathrm{b}}$ \\
$<30, n(\%)$ & $39(39.0)$ \\
$30-60, n(\%)$ & $31(31.0)$ \\
$>60, n(\%)$ & $30(30.0)$ \\
BMI $\left(\mathrm{kg} / \mathrm{m}^{2}\right)$ & $24.0 \pm 4.1^{\mathrm{a}}$ \\
$<21, n(\%)$ & $17(17.0)$ \\
$21-27, n(\%)$ & $62(62.0)$ \\
$>27, n(\%)$ & $21(21.0)$ \\
Indications for implantation & \\
AVCD, $n(\%)$ & $60(60.0)$ \\
SSS, $n(\%)$ & $30(30.0)$ \\
AFSVR, $n(\%)$ & $10(10.0)$ \\
LOS-B (days) & $6(3 ; 11)^{\mathrm{b}}$ \\
Dual-chamber pacemaker & $(80)$ \\
\hline
\end{tabular}

eGFR, estimated glomerular filtration rate; BMI, body mass index; AVCD, atrioventricular conduction dysfunction; SSS, sick sinus syndrome; AFSVR, atrial fibrillation with slow ventricular response; LOS-B, length of hospital stay before permanent pacemaker implantation

${ }^{\mathrm{a}}$ Mean \pm SD

${ }^{\mathrm{b}}$ Medians with interquartile range

a small amount pericardial effusion. Except for the pigtail catheter placement for pneumothorax, all four of the other patients were managed successfully with conservative observation, without the necessity of fluid resuscitation, antibiotic treatment, re-intervention, or any invasive procedure. Despite the complications, all the five patients continued to have stable vital signs. No other significant complication was noted, such as wound or pacing system infection, cardiac tamponade, hemothorax, lead or pulse generator problem, or procedure-related mortality. 
The follow-up duration was $4.0 \pm 2.7$ years, with the longest follow-up of 11.1 years. The survival rates at 1, 2, 3, 5, and 7 years were $90 \%, 76 \%, 54 \%, 32 \%$, and $16 \%$, respectively. By the end of the study, 54 patients (54\%) had died. Of the 54 deceased patients, 40 (74.1\%) died of non-cardiac causes. The most common non-cardiac cause of death was pneumonia which occurred in 14 patients (35\%), followed by 12 with sepsis (30\%), 8 with cancer (20\%), 5 who suffered cerebral vascular accidents (12.5\%), and 1 who experienced trauma $(2.5 \%)$. Eleven patients $(20.4 \%)$ died of cardiac causes, and five (45.5\%) died of unknown causes despite attempted resuscitation. No deaths were PPM-related. The causes of mortality are shown in Table 2.

\section{Predictors of survival}

In Cox univariate analysis, the following variables were significantly associated with lower cumulative survival rate: dyspnea as the major presenting symptom, eGFR $<30 \mathrm{ml} /$ $\mathrm{min} / 1.73 \mathrm{~m}^{2}, \mathrm{BMI}<21 \mathrm{~kg} / \mathrm{m}^{2}$, AFSVR as the indication for PPM implantation, and longer LOS-B (Table 3). Cox multivariate analysis was performed by including the variables with $p$ value $<0.2$ from the univariate analysis. Cox multivariate analysis showed that major symptoms, eGFR, BMI, and LOS-B, were independently associated with survival. We found that the following criteria were associated with worse long-term survival: patients with dyspnea as the major presenting symptom (HR 2.88, 95\% CI 1.27-6.55, $p=0.01$ ), eGFR $<30 \mathrm{ml} / \mathrm{min} / 1.73 \mathrm{~m}^{2}$ (HR 4.07, 95\% CI 1.95-8.52, $p<0.001$ ), BMI $<21 \mathrm{~kg} / \mathrm{m}^{2}$ (HR 2.50, 95\% CI 1.16-5.39, $p=0.02$ ) and longer LOS-B (HR 1.03, 95\% CI 1.02-1.05, $p<0.001)$. Age was not significantly associated with worse

Table 2 Causes of death in 100 patients aged 80 or older who received permanent pacemaker implantation during follow-up of $4.0 \pm 2.7$ years

\begin{tabular}{ll}
\hline & No. \\
\hline Non-cardiac causes & 40 \\
Pneumonia, $n(\%)$ & $14(35)$ \\
Sepsis, $n(\%)$ & $12(30)$ \\
Cancer, $n(\%)$ & $8(20)$ \\
Cerebral vascular accident, $n(\%)$ & $5(12.5)$ \\
Trauma, $n(\%)$ & $1(2.5)$ \\
Cardiac causes & 11 \\
Resuscitation for unknown cause, $n(\%)$ & $5(45.5)$ \\
Acute myocardial infarction, $n(\%)$ & $3(27.3)$ \\
Congestive heart failure, $n(\%)$ & $3(27.3)$ \\
Unknown & 3 \\
Permanent pacemaker related & 0 \\
Total & 54 \\
\hline
\end{tabular}

long-term survival (HR 1.06, 95\% CI 0.99-1.14, $p=0.09$ ) (Table 3).

Kaplan-Meier curves reveal that patients with an eGFR $<30 \mathrm{ml} / \mathrm{min} / 1.73 \mathrm{~m}^{2}$ had significantly lower cumulative survival compared to those with an eGFR $>60 \mathrm{ml} /$ $\min / 1.73 \mathrm{~m}^{2}$ ( $p=0.004$ ) (Fig. 1a). No significant difference was noted between the curves of eGFR 30-60 and $>60 \mathrm{ml} /$ $\mathrm{min} / 1.73 \mathrm{~m}^{2}$. Patients with eGFR $<30 \mathrm{ml} / \mathrm{min} / 1.73 \mathrm{~m}^{2}$ had significantly lower cumulative survival compared to others ( $p=0.002$ ) (Fig. 1b). Patients with BMI of $<21 \mathrm{~kg} / \mathrm{m}^{2}$ had significantly lower cumulative survival compared to those with BMI of $21-27 \mathrm{~kg} / \mathrm{m}^{2}(p=0.01)$ (Fig. 2a) and compared to those with BMI $\geq 21 \mathrm{~kg} / \mathrm{m}^{2}$ ( $p=0.01$ ) (Fig. $2 \mathrm{~b}$ ). When LOS-B was categorized into $\leq 10$ and $>10$ days (the third quartile of LOS-B), the median survival duration in patients with an LOS-B of $>10$ days was significantly shorter than others (2.8 years, 95\% CI 1.2-4.4 years, versus 6.9 years, 95\% CI 5.2-8.7 years, $p=0.001$ ) (Fig. 3).

\section{Length of stay before PPM implantation (LOS-B)}

Median LOS-B was 6 days. The LOS-B was significantly longer in 35 patients (35\%) due to systemic infection with a need for parenteral antibiotic treatment $[11(5 ; 8)$ days versus $5(2 ; 8)$ days, $p<0.001]$, in 9 patients $(9 \%)$ due to respiratory failure with mechanical ventilator support $[13(11 ; 24)$ days versus $5(3 ; 10)$ days, $p<0.001]$, in 21 patients $(21 \%)$ due to acute kidney injury resulting in electrolyte imbalance and fluid overload $[13(9 ; 20)$ days versus $5(3 ; 9)$ days, $p<0.001$ ], in 12 patients $(12 \%)$ who needed cardiac catheterization to estimate CAD $[10.5(8 ; 13.5)$ days versus 5 $(3 ; 11)$ days, $p=0.006]$, and in 5 patients $(5 \%)$ who needed coronary artery intervention for significant CAD [13 (8; 32 ) days versus $5(3 ; 11)$ days, $p=0.02]$. The LOS-B was insignificantly longer in seven patients $(7 \%)$ due to gastrointestinal tract bleeding $[8(3 ; 10)$ days versus $6(3 ; 11)$ days, $p=0.7]$.

\section{Discussion}

This study analyzed the pre-PPM implantation predictors of long-term survival in patients aged 80 or older. The main findings of this study are as follows: (1) LOS-B, eGFR, $\mathrm{BMI}$, and dyspnea as the major presenting symptoms were independent predictors of long-term survival. (2) The survival rates were $90 \%, 76 \%, 54 \%, 32 \%$, and $16 \%$ at $1,2,3,5$, and 7 years, respectively. (3) Most of the patients (74.1\%) died of non-cardiac causes.

Previously, Udo et al. performed a study focusing on the long-term outcomes of cardiac pacing in octogenarians and nonagenarians. They found that age at the time of implantation, male gender, congestive heart failure, coronary 
Table 3 Univariate and multivariate analyses for predictors of all-cause mortality in 100 patients aged 80 or over who received permanent pacemaker implantation

\begin{tabular}{|c|c|c|c|c|}
\hline \multirow[t]{2}{*}{ Variables } & \multicolumn{2}{|l|}{ Univariate analysis } & \multicolumn{2}{|c|}{ Multivariate analysis } \\
\hline & HR (95\% CI) & $p$ value & HR (95\% CI) & $p$ value \\
\hline Age at implantation ${ }^{\mathrm{a}}$ & $1.05(0.99-1.11)$ & 0.10 & $1.06(0.99-1.14)$ & 0.09 \\
\hline Male gender & $0.73(0.43-1.24)$ & 0.25 & & \\
\hline Admitted from ED & $1.22(0.67-2.25)$ & 0.52 & & \\
\hline Ejection fraction $(\%)^{\mathrm{b}}$ & $0.99(0.97-1.02)$ & 0.66 & & \\
\hline Major presenting symptom & & 0.09 & & 0.04 \\
\hline Dizziness & Reference & & Reference & \\
\hline Syncope, near syncope & $1.59(0.70-3.64)$ & 0.27 & $1.90(0.77-4.71)$ & 0.17 \\
\hline Dyspnea & $2.18(1.07-4.47)$ & 0.03 & $2.88(1.27-6.55)$ & 0.01 \\
\hline Hypertension & $1.03(0.50-2.14)$ & 0.93 & & \\
\hline Diabetes mellitus & $1.37(0.78-2.42)$ & 0.28 & & \\
\hline Coronary artery disease & $1.29(0.69-2.43)$ & 0.43 & & \\
\hline Valvular heart disease & $1.47(0.81-2.67)$ & 0.21 & & \\
\hline Cerebral vascular accident & $1.34(0.74-2.44)$ & 0.34 & & \\
\hline COPD & $1.07(0.52-2.19)$ & 0.87 & & \\
\hline Atrial arrhythmia & $0.79(0.45-1.39)$ & 0.42 & & \\
\hline eGFR (ml/min $\left./ 1.73 \mathrm{~m}^{2}\right)$ & & 0.01 & & $<0.001$ \\
\hline$>60$ & Reference & & Reference & \\
\hline $30-60$ & $1.05(0.55-1.99)$ & 0.88 & $1.21(0.59-2.48)$ & 0.60 \\
\hline$<30$ & $2.56(1.31-5.00)$ & 0.006 & $4.07(1.95-8.52)$ & $<0.001$ \\
\hline BMI $\left(\mathrm{kg} / \mathrm{m}^{2}\right)$ & & 0.04 & & 0.03 \\
\hline $21-27$ & Reference & & Reference & \\
\hline$<21$ & $2.41(1.19-4.90)$ & 0.01 & $2.50(1.16-5.39)$ & 0.02 \\
\hline$>27$ & $1.09(0.55-2.18)$ & 0.79 & $0.71(0.32-1.57)$ & 0.39 \\
\hline Indications for implantation & & 0.03 & & 0.15 \\
\hline SSS & Reference & & Reference & \\
\hline AVCD & $1.89(0.96-3.74)$ & 0.07 & $1.11(0.52-2.39)$ & 0.79 \\
\hline AfSVR & $3.42(1.39-8.40)$ & 0.007 & $2.31(0.90-5.90)$ & 0.08 \\
\hline LOS-B (days) ${ }^{b}$ & $1.03(1.01-1.04)$ & $<0.001$ & $1.03(1.02-1.05)$ & $<0.001$ \\
\hline
\end{tabular}

$\mathrm{HR}$, hazard ratio; CI, confidence interval; ED, emergency department; COPD, chronic obstructive pulmonary disease; eGFR, estimated glomerular filtration rate; BMI, body mass index; SSS, sick sinus syndrome; AVCD, atrioventricular conduction dysfunction; AFSVR, atrial fibrillation with slow ventricular response; LOS-B, length of hospital stay before pacemaker implantation

${ }^{\text {a}}$ Per 1 year increase in age

${ }^{b}$ Per unit increase pathology, and diabetes mellitus were independent predictors of all-cause mortality [7]. However, they did not include informative clinical data such as symptoms, LVEF, eGFR, and the length of hospital stay as potential predictors of long-term survival prior to PPM implantation. We included these potential predictors prior to PPM implantation in our study to further investigate factors predicting long-term survival in patients aged 80 and above.

\section{Survival after PPM implantation in patients aged 80 or older}

Our study revealed that the survival rates after PPM implantation in patients aged 80 or older were $90 \%, 76 \%, 54 \%$,
$32 \%$, and $16 \%$ at $1,2,3,5$, and 7 years, respectively. Most of the patients $(74.1 \%)$ died of non-cardiac causes. These findings are similar to the results obtained by Udo et al., which showed $86 \%, 75 \%$, and $49 \%$ at 1,2 , and 5 years, respectively; $69.8 \%$ of those patients died of non-cardiac causes [7].

The duration of time from the initial implantation to replacing a PPM generator varied between 6 and 7 years in different studies $[17,18]$. In our study, survival duration was from less than 1 year to longer than 10 years. Actually, $16 \%$ of patients remained alive 7 years after PPM implantation. This implies that, with proper care, some of very old patients can still survive for a significantly long period of years. Therefore, correctly identifying them before PPM implantation and optimizing the PPM program settings 


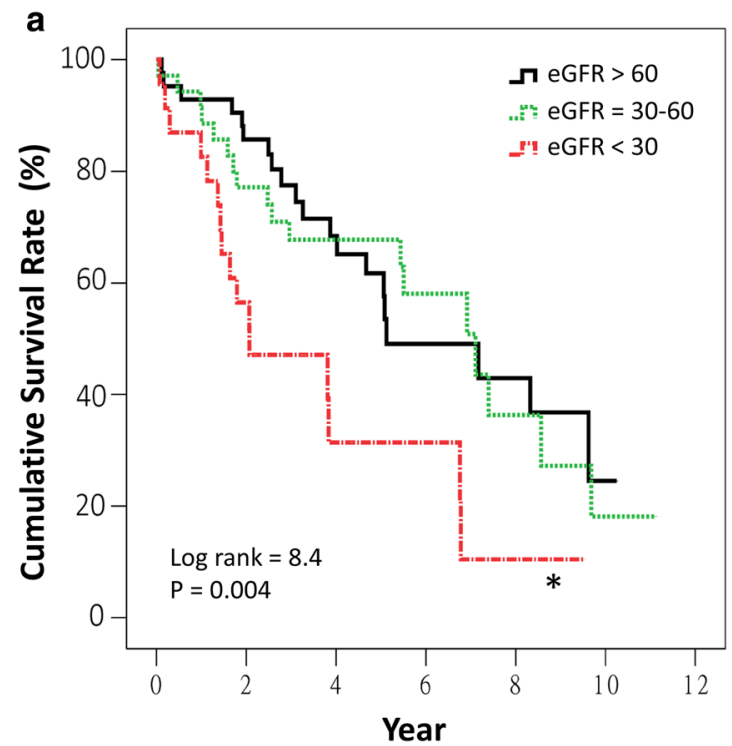

Fig. 1 Kaplan-Meier survival curves for all-cause mortality after permanent pacemaker implantation in patients aged 80 or older categorized by the estimated glomerular filtration rates (eGFR) of $>60$,

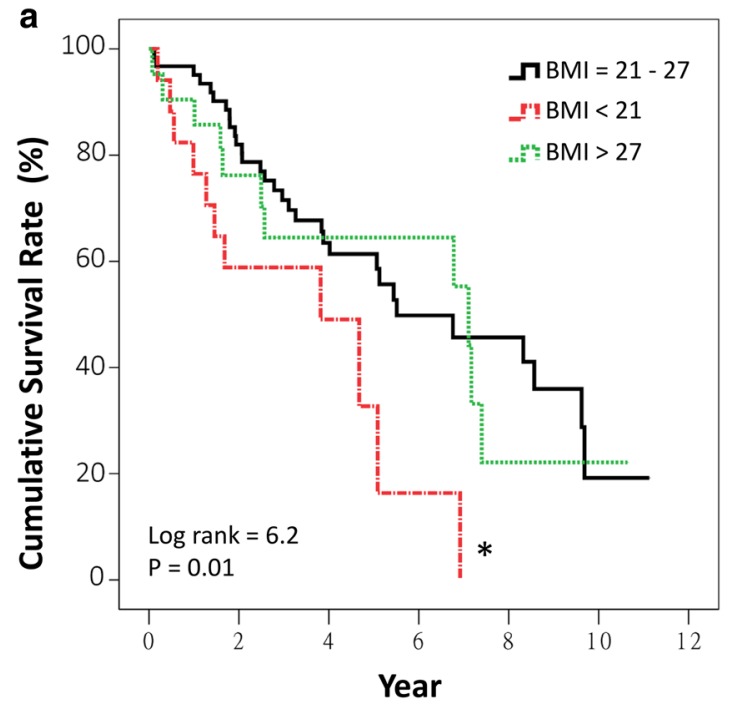

Fig. 2 Kaplan-Meier survival curves for all-cause mortality after permanent pacemaker implantation in patients aged 80 or older categorized by body mass index $(\mathrm{BMI})<21,21-27$, and $>27 \mathrm{~kg} / \mathrm{m}^{2}$ (a),

during follow-up were essential to enhance PPM longevity and avoid repeated generator replacement. On the other hand, there were $10 \%$ of patients died within 1 year after PPM implantation. Whether or not to proceed with PPM implantation in these patients is not only a medical or economic issue but also an ethical one. Our findings suggested that, for patients aged 80 and above with the following clinical characteristics: longer LOS-B, eGFR $<30 \mathrm{ml} /$

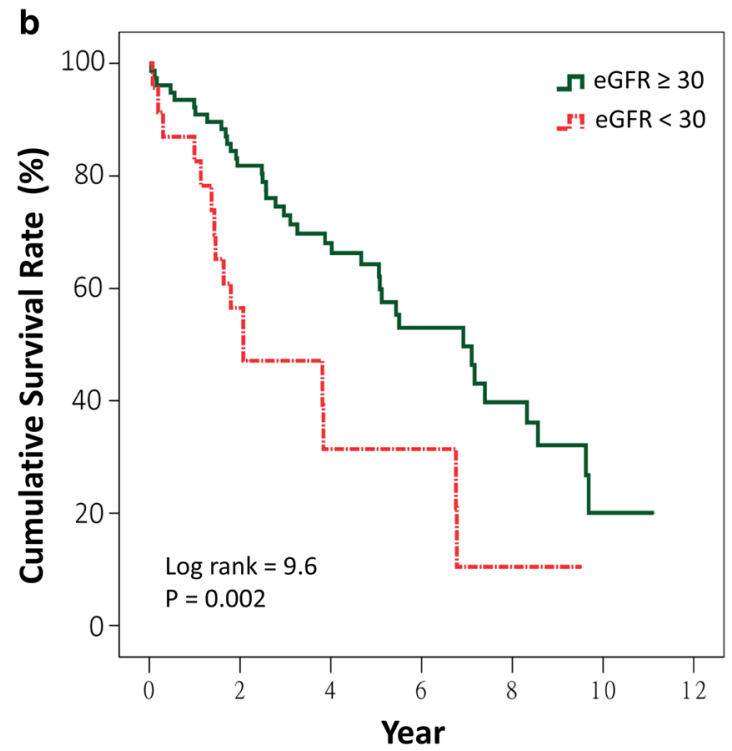

$30-60$, and $<30 \mathrm{ml} / \mathrm{min} / 1.73 \mathrm{~m}^{2}(\mathbf{a})$, and categorized by $\geq 30$ and $<30 \mathrm{ml} / \mathrm{min} / 1.73 \mathrm{~m}^{2}$ (b). ${ }^{*} p=0.004$, compared to eGFR $>60 \mathrm{ml} /$ $\min / 1.73 \mathrm{~m}^{2}$

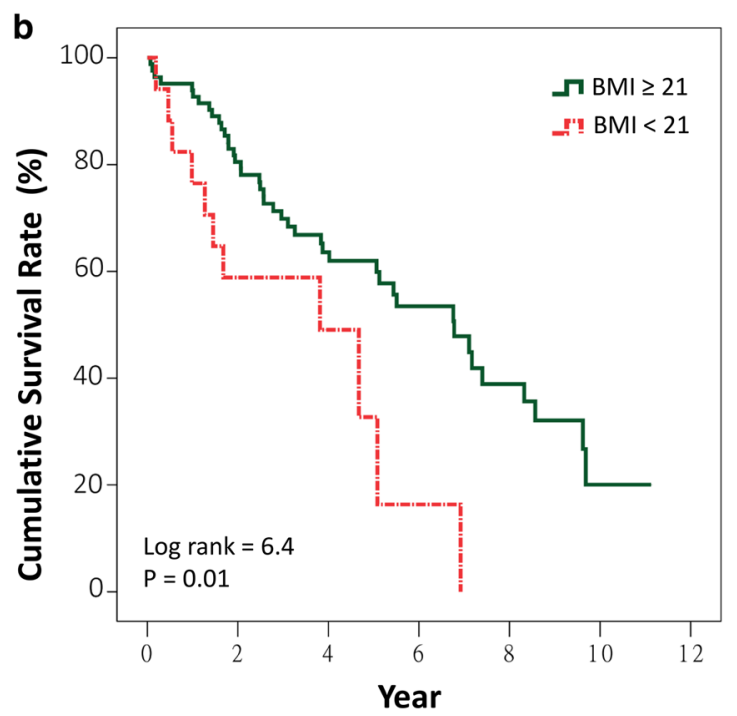

and categorized by $\geq 21$ and $<21 \mathrm{~kg} / \mathrm{m}^{2}$ (b). ${ }^{*} p=0.01$, compared to $\mathrm{BMI}=21-27 \mathrm{~kg} / \mathrm{m}^{2}$

$\min / 1.73 \mathrm{~m}^{2}$, BMI $<21 \mathrm{~kg} / \mathrm{m}^{2}$, or dyspnea as the major presenting symptom, comprehensive geriatric assessment should be considered to perform before PPM implantation with the purpose of planning and/or delivering medical, psychosocial, and rehabilitative care [19]. In addition to identifying these patients early, decision-making should be shared with patients and their families. Interventions like participating in a rehabilitation program and a better 


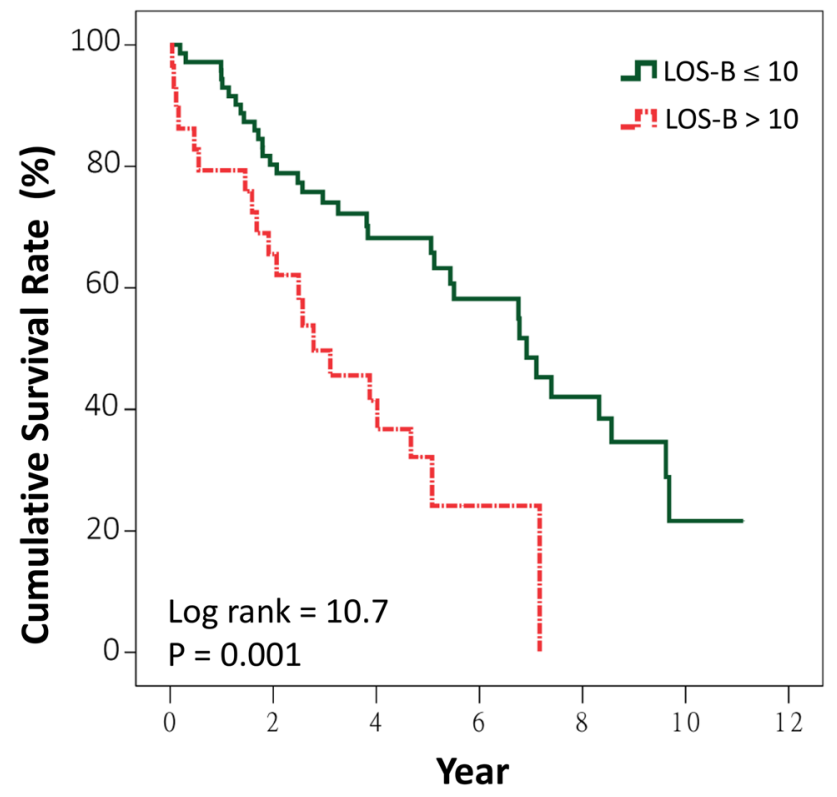

Fig. 3 Kaplan-Meier survival curves for all-cause mortality after permanent pacemaker implantation in patients aged 80 or older stratified by the length of hospital stay before permanent pacemaker implantation (LOS-B)

nutritional support may also be helpful for this population at risk.

\section{LOS-B as a predictor of long-term survival}

Our study suggested that longer LOS-B was associated with shorter long-term survival. Although the mechanisms are not entirely clear, longer LOS-B may be one indicator of frail status, which predicts poor long-term survival. Furthermore, we found that causes of prolonged LOS-B were substantially associated with a variety of coexisting multiple systemic diseases. It is not uncommon to encounter such complex conditions in clinical practice. When hospitalized, geriatric patients often present with active problems in multiple organs due to compromised homeostatic mechanisms as a result of aging-associated decline in functional reserve across multiple physiological systems [20]. Multiple comorbidities resulted in prolonged length of hospital stay. The previous studies have already reported that frailty and prolonged length of hospital stay in frail patients $[11,21,22]$ are associated with poor long-term survival [23, 24].

To the best of our knowledge, no previous study has addressed the relation between length of stay before pacemaker implantation (LOS-B) and long-term survival. Most prior studies of geriatric patients receiving PPM implants did not include data on LOS-B [4-7, 25, 26], or only noted the total length of hospital stay [27] or length of stay after the procedure [28]. Since multiple organ problems often delay PPM implantation, LOS-B could be a practical indicator for predicting long-term survival in geriatric patients before the procedure.

\section{The eGFR as a predictor of long-term survival}

Our study results suggested that eGFR $<30 \mathrm{ml} / \mathrm{min} / 1.73 \mathrm{~m}^{2}$ before PPM implantation is a predictor of worse outcomes among patients aged 80 and above. CKD was associated with multiple comorbidities [29]. In addition, CKD not only correlated with functional limitations [30], but also with greater likelihood of frailty, which itself predicts poor survival $[14,31]$. There is increasing recognition that CKD is associated with increased all-cause mortality in specific populations [14, 32-34]. To the best of our knowledge, no previous study has focused on the association between eGFR and long-term survival in patients receiving PPM implantation. A better understanding of patients' eGFR before PPM implantation can be helpful for predicting prognosis.

\section{BMI as a predictor of long-term survival}

In line with the previous studies in general or older populations, we found that being underweight is associated with higher mortality [35-38]. For the aged, being underweight might signal loss of appetite, poor nutrition, and/or poor emotional well-being. These could lead to limited daily activity, sarcopenia, frailty, and increased risk of mortality $[39,40]$.

Another finding of the study is that BMI $>27 \mathrm{~kg} / \mathrm{m}^{2}$ was not associated with worse long-term survival. The relation between overweight-obesity and mortality in older people remains controversial and has been described with either U- or L-shaped curves. The U-shaped curves represent significantly increased mortality observed both in underweight and overweight-obese people [35]. The L-shaped curves represent significantly increased mortality only among the underweight, but not among the overweight-obese people [36-38, 41]. This is referred to as the obesity paradox [42]. Theoretically, the L-shaped curves are expected to occur more frequently in older study populations in whom obesity-related diseases like cardiovascular or cerebrovascular diseases are not the leading cause of mortality [37]. Our study focused on very old patients whose leading causes of mortality that we found to be non-cardiovascular disease. The obesity paradox does appear in our study cohort.

Only one previous study has addressed BMI and longterm survival in older patients receiving PPM implantation. In contrast to our results, the study by Udo et al. showed no association between BMI and long-term survival [7]. Since the previous studies on non-PPM recipients suggested a nonlinear relation between BMI and survival [35-38, 41], the negative findings by Udo et al. might be due to different 
ethnicities of the patients or to their study design, which did not divide BMI into different categories.

\section{Dyspnea as a predictor of long-term survival}

Our study found that patients with dyspnea as the major initial symptom were associated with worse long-term survival compared with those who presented with symptoms of dizziness, pre-syncope, or syncope. Recent studies have suggested that dyspnea is correlated with cardiopulmonary and physical performance impairments, and could be a potential marker of frailty in adults. It is not only a symptom but also associated with increased mortality from all causes $[8,43]$. Although bradycardia may cause a variety of signs and symptoms, exercise intolerance may indicate advanced dysregulation in response to bradycardia. Very few previous studies have included the symptom of dyspnea as a potential predictor for long-term survival in aged patients receiving PPM implantation [6]. Our study suggested that dyspnea is not only a symptom of bradycardia, but also it might have important prognostic implications for long-term survival in older patients receiving PPM implantation.

\section{Study limitations}

This is a single hospital retrospective study and we could not exclude selection-bias. The relatively small sample size also reduces the power of the study. Moreover, due to limited data available through chart review, we did not include psychosocial and functional assessments, which are important components of comprehensive geriatric assessment. Furthermore, our study focused on survival duration but did not mention quality of life, which is also an important issue. The results presented here should be confirmed by prospective, large-scale randomized-controlled trials with long-term follow-up.

\section{Conclusions}

Our study shows the cumulative 3-year survival rate after PPM implantation in patients aged 80 or older was $54 \%$. Survival duration varied from less than 1 year to longer than 10 years. Three-fourths of the patients died of noncardiac causes. Longer LOS-B, eGFR $<30 \mathrm{ml} / \mathrm{min} / 1.73 \mathrm{~m}^{2}$, $\mathrm{BMI}<21 \mathrm{~kg} / \mathrm{m}^{2}$, and dyspnea as the major presenting symptom predicted worse long-term survival. Assessment of these risk factors before PPM implantation is informative for clinical practice and decision-making.

\section{Compliance with ethical standards}

Conflict of interest All authors have no conflict of interest to declare.
Ethical standards This study was approved by the Institutional Review Board of Chang Gung Medical Foundation.

Statement of human and animal rights The study including human participants has been performed in accordance with the ethical standards of the Declaration of Helsinki and its later amendments.

Informed consent No informed consent requirement was required by the Institutional Review Board of Chang Gung Medical Foundation.

Open Access This article is distributed under the terms of the Creative Commons Attribution 4.0 International License (http://creativeco mmons.org/licenses/by/4.0/), which permits unrestricted use, distribution, and reproduction in any medium, provided you give appropriate credit to the original author(s) and the source, provide a link to the Creative Commons license, and indicate if changes were made.

\section{References}

1. United Nations, Department of Economic and Social Affairs, Population Division (2017) World population prospects: the 2017 revision, key findings and advance tables. Working Paper No. ESA/P/WP/248. https://esa.un.org/unpd/wpp/Publications/ Files/WPP2017_KeyFindings.pdf. Accessed 7 Feb 2018

2. Greenspon AJ, Patel JD, Lau E et al (2012) Trends in permanent pacemaker implantation in the United States from 1993 to 2009: increasing complexity of patients and procedures. J Am Coll Cardiol 60:1540-1545. https://doi.org/10.1016/j.jacc.2012.07.017

3. Epstein AE, DiMarco JP, Ellenbogen KA et al (2013) 2012 ACCF/ AHA/HRS focused update incorporated into the ACCF/AHA/ HRS 2008 guidelines for device-based therapy of cardiac rhythm abnormalities: a report of the American College of Cardiology Foundation/American Heart Association Task Force on Practice Guidelines and the Heart Rhythm Society. J Am Coll Cardiol 61:e6-e75. https://doi.org/10.1016/j.jacc.2012.11.007

4. Schmidt B, Brunner M, Olschewski M et al (2003) Pacemaker therapy in very elderly patients: long-term survival and prognostic parameters. Am Heart J 146:908-913. https://doi.org/10.1016/ s0002-8703(03)00453-8

5. Jahangir A, Shen WK, Neubauer SA et al (1999) Relation between mode of pacing and long-term survival in the very elderly. J Am Coll Cardiol 33:1208-1216

6. Shen WK, Hayes DL, Hammill SC et al (1996) Survival and functional independence after implantation of a permanent pacemaker in octogenarians and nonagenarians. A population-based study. Ann Intern Med 125:476-480

7. Udo EO, van Hemel NM, Zuithoff NP et al (2012) Long-term outcome of cardiac pacing in octogenarians and nonagenarians. Europace 14:502-508 https://doi.org/10.1093/europace/eur329

8. Smith AK, Currow DC, Abernethy AP et al (2016) Prevalence and outcomes of breathlessness in older adults: a national population study. J Am Geriatr Soc 64:2035-2041. https://doi.org/10.1111/ jgs. 14313

9. Warnock DG, Delanaye P, Glassock RJ (2017) Risks for allcause mortality: stratified by age, estimated glomerular filtration rate and albuminuria. Nephron 136:292-297. https://doi. org/10.1159/000455197

10. Shah KS, Xu H, Matsouaka RA et al (2017) Heart failure with preserved, borderline, and reduced ejection fraction: 5-year outcomes. J Am Coll Cardiol. https://doi.org/10.1016/j.jacc.2017.08.074 
11. Hubbard RE, Peel NM, Samanta M et al (2017) Frailty status at admission to hospital predicts multiple adverse outcomes. Age Ageing 46:801-806. https://doi.org/10.1093/ageing/afx081

12. Nishimura RA, Otto CM, Bonow RO et al (2017) 2017 AHA/ ACC focused update of the 2014 AHA/ACC guideline for the management of patients with valvular heart disease: a report of the American College of Cardiology/American Heart Association Task Force on Clinical Practice Guidelines. Circulation 135:e1159-e1195. https://doi.org/10.1161/CIR.000000000000050 3

13. Stevens PE, Levin A (2013) Evaluation and management of chronic kidney disease: synopsis of the kidney disease: improving global outcomes 2012 clinical practice guideline. Ann Intern Med 158:825-830. https://doi.org/10.7326/0003-4819-158-11-20130 6040-00007

14. Montesanto A, De Rango F, Berardelli M et al (2014) Glomerular filtration rate in the elderly and in the oldest old: correlation with frailty and mortality. Age 36:9641. https://doi.org/10.1007/s1135 7-014-9641-4

15. Tsai AC, Liou J-C, Chang M-C et al (2007) Influence of diet and physical activity on aging-associated body fatness and anthropometric changes in older Taiwanese. Nutr Res 27:245-251. https ://doi.org/10.1016/j.nutres.2007.03.002

16. Tsai AC, Ho CS, Chang MC (2007) Population-specific anthropometric cut-points improve the functionality of the Mini Nutritional Assessment (MNA) in elderly Taiwanese. Asia Pac J Clin Nutr 16:656-662

17. Hauser RG, Hayes DL, Kallinen LM et al (2007) Clinical experience with pacemaker pulse generators and transvenous leads: an 8-year prospective multicenter study. Heart Rhythm 4:154-160. https://doi.org/10.1016/j.hrthm.2006.10.009

18. de Vries LM, Leening MJG, Dijk WA et al (2017) Trends in service time of pacemakers in The Netherlands: a long-term nationwide follow-up study. Neth Heart J 25:581-591. https://doi. org/10.1007/s12471-017-1024-x

19. Rubenstein LZ, Stuck AE, Siu AL et al (1991) Impacts of geriatric evaluation and management programs on defined outcomes: overview of the evidence. J Am Geriatr Soc 39:8S-16S (discussion 17S-18S)

20. Resnick NM, Marcantonio ER (1997) How should clinical care of the aged differ? Lancet 350:1157-1158. https://doi.org/10.1016/ s0140-6736(05)63817-2

21. Rose M, Pan H, Levinson MR et al (2014) Can frailty predict complicated care needs and length of stay? Inter Med J 44:800-805. https://doi.org/10.1111/imj.12502

22. Hope AA, Adeoye O, Chuang EH et al (2017) Pre-hospital frailty and hospital outcomes in adults with acute respiratory failure requiring mechanical ventilation. J Crit Care 44:212-216. https ://doi.org/10.1016/j.jcrc.2017.11.017

23. Xue QL (2011) The frailty syndrome: definition and natural history. Clin Geriatr Med 27:1-15. https://doi.org/10.1016/j. cger.2010.08.009

24. Clegg A, Young J, Iliffe S et al (2013) Frailty in elderly people. Lancet 381:752-762. https://doi.org/10.1016/s0140 $-6736(12) 62167-9$

25. Chao TF, Liu CJ, Tuan TC et al (2014) Long-term prognosis of patients older than ninety years after permanent pacemaker implantation: does the procedure save the patients? Can J Cardiol 30:1196-1201. https://doi.org/10.1016/j.cjca.2014.04.010

26. Shen WK, Hammill SC, Hayes DL et al (1994) Long-term survival after pacemaker implantation for heart block in patients $>$ or $=65$ years. Am J Cardiol 74:560-564

27. Mandawat A, Curtis JP, Mandawat A et al (2013) Safety of pacemaker implantation in nonagenarians: an analysis of the healthcare cost and utilization project-nationwide inpatient sample. Circulation 127(1465e1451-1452):1453-1465. https:// doi.org/10.1161/circulationaha.113.001434

28. Stevenson RT, Lugg D, Gray R et al (2012) Pacemaker implantation in the extreme elderly. J Interv Cardiac Electrophysiol 33:51-58. https://doi.org/10.1007/s10840-011-9618-5

29. Webster AC, Nagler EV, Morton RL et al (2017) Chronic kidney disease. Lancet 389:1238-1252. https://doi.org/10.1016/s0140 $-6736(16) 32064-5$

30. Pedone C, Corsonello A, Bandinelli S et al (2012) Relationship between renal function and functional decline: role of the estimating equation. J Am Med Dir Assoc 13:84.e11-84.e84. https://doi. org/10.1016/j.jamda.2011.01.009

31. Chowdhury R, Peel NM, Krosch M et al (2017) Frailty and chronic kidney disease: a systematic review. Arch Gerontol Geriatr 68:135-142. https://doi.org/10.1016/j.archger.2016.10.007

32. Li YH, Lin GM, Lin CL et al (2013) Relation of estimated glomerular filtration rate and body mass index to mortality in nondialysis patients with coronary artery disease: a report from the ET-CHD registry, 1997-2003. J Cardiol 62:144-150. https://doi. org/10.1016/j.jjcc.2013.03.016

33. Go AS, Chertow GM, Fan D et al (2004) Chronic kidney disease and the risks of death, cardiovascular events, and hospitalization. N Engl J Med 351:1296-1305. https://doi.org/10.1056/NEJMo a041031

34. Daimee UA, Moss AJ, Biton Y et al (2015) Long-term outcomes with cardiac resynchronization therapy in patients with mild heart failure with moderate renal dysfunction. Circ Heart Fail 8:725732. https://doi.org/10.1161/circheartfailure.115.002082

35. Peter RS, Mayer B, Concin H et al (2005) The effect of age on the shape of the BMI-mortality relation and BMI associated with minimum all-cause mortality in a large Austrian cohort. Int J Obes 39:530-534. https://doi.org/10.1038/ijo.2014.168

36. Ng TP, Jin A, Chow KY et al (2017) Age-dependent relationships between body mass index and mortality: Singapore longitudinal ageing study. PLoS One 12:e0180818 https://doi.org/10.1371/ journal.pone.0180818

37. Tsai AC, Hsiao ML (2012) The association of body mass index (BMI) with all-cause mortality in older Taiwanese: results of a national cohort study. Arch Gerontol Geriatr 55:217-220. https ://doi.org/10.1016/j.archger.2011.08.006

38. Tamakoshi A, Yatsuya H, Lin Y et al (2010) BMI and all-cause mortality among Japanese older adults: findings from the Japan collaborative cohort study. Obesity (Silver Spring Md) 18:362369. https://doi.org/10.1038/oby.2009.190

39. Heitmann BL, Erikson H, Ellsinger BM et al (2000) Mortality associated with body fat, fat-free mass and body mass index among 60-year-old swedish men - a 22-year follow-up. The study of men born in 1913. Int J Obes Relat Metab Disord 24:33-37

40. Janssen I, Heymsfield SB, Ross R (2002) Low relative skeletal muscle mass (sarcopenia) in older persons is associated with functional impairment and physical disability. J Am Geriatr Soc 50:889-896

41. Auyeung TW, Lee JS, Leung J et al (2010) Survival in older men may benefit from being slightly overweight and centrally obese-a 5 -year follow-up study in 4000 older adults using DXA. J Gerontol Ser A Biol Sci Med Sci 65:99-104. https://doi.org/10.1093/geron a/glp099

42. Oreopoulos A, Kalantar-Zadeh K, Sharma AM et al (2009) The obesity paradox in the elderly: potential mechanisms and clinical implications. Clin Geriatr Med 25:643-659. https://doi. org/10.1016/j.cger.2009.07.005 viii

43. Hegendorfer E, Vaes B, Mathei C et al (2017) Correlates of dyspnoea and its association with adverse outcomes in a cohort of adults aged 80 and over. Age Ageing 46:994-1000. https://doi. org/10.1093/ageing/afx095 